This item was submitted to Loughborough's Research Repository by the author.

Items in Figshare are protected by copyright, with all rights reserved, unless otherwise indicated.

\title{
A possible hardware architecture of wireless sensor nodes
}

PLEASE CITE THE PUBLISHED VERSION

PUBLISHER

(C) IEEE

VERSION

VoR (Version of Record)

LICENCE

CC BY-NC-ND 4.0

\section{REPOSITORY RECORD}

Zhu, Zhenhuan, and Shuang-Hua Yang. 2019. "A Possible Hardware Architecture of Wireless Sensor Nodes". figshare. https://hdl.handle.net/2134/4131. 
This item was submitted to Loughborough's Institutional Repository (https://dspace.lboro.ac.uk/) by the author and is made available under the following Creative Commons Licence conditions.

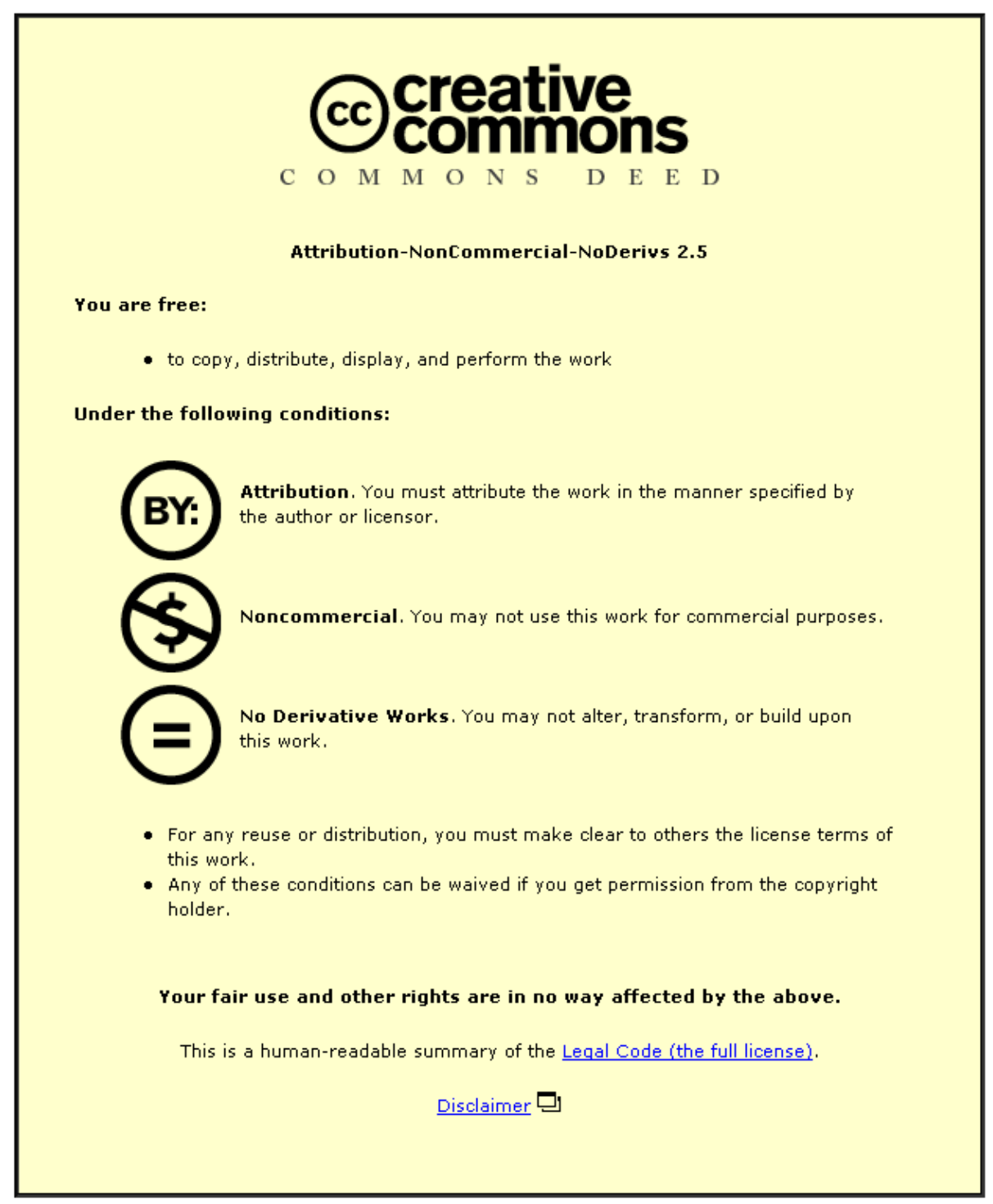

For the full text of this licence, please go to: http://creativecommons.org/licenses/by-nc-nd/2.5/ 


\title{
A Possible Hardware Architecture of Wireless Sensor Nodes
}

\author{
Zhenhuan Zhu and Shuang-Hua Yang (SMIEEE)
}

\begin{abstract}
The paper focuses on the hardware architectures of wireless sensor nodes based on the IEEE 802.15.4/ZigBee protocol. It reviews the solutions provided by some main commonly used chip manufacturers, lists some of typical components and part of their parameters related to power consumption. The paper discusses the architecture of a canonical node and its subsystems, and analyzes the special requirements of wireless sensor nodes for building fire safety. A possible hardware architecture, centering routine transactions, of wireless sensor node, is presented.

KEY WORDS: Wireless sensor nodes, ZigBee, Hardware architecture, Building fire safety, Centering routine transactions.
\end{abstract}

\section{INTRODUCTION}

$\mathrm{W}$ IRELESS sensor networks (WSNs) play an important role for acquiring information from complex physical environment. More and more research is focused on WSNs in last few years. WSNs consist of small nodes with sensing, computation, and wireless communication capabilities. Except for the capabilities above, it is necessary to consider problems such as power consumption in the design of wireless sensor system. Many routing, power management, and data dissemination protocols have been specifically designed for WSNs where energy awareness is an essential design issue [1]. Sensor nodes are battery driven and hence operate on an extremely frugal energy budget. Further, they must have a lifespan on the order of months to years, since battery replacement is not an option for networks with thousands of physically embedded nodes. The network lifespan can be maximized only by incorporating energy-awareness into every stage of wireless sensor network design and operation, thus empowering the system with the ability to make dynamic tradeoffs between energy consumption, system performance, and operational fidelity [2]. The paper reviews the hardware architecture of a canonical node and its sub-functions with energy-awareness. The typical products of wireless sensor nodes and their structures are discussed, and a possible hardware architecture is proposed so that the power consumption can be significantly reduced and the performance of sensor node might be improved further.

Mr. Z. Zhu, PhD student, in the Department of Computer Science, Loughborough University, LE11 3TU, UK. E-mail: Z.Zhu2@lboro.ac.uk.

Dr. S. H. Yang, Senior Lecturer in the Department of Computer Science, Loughborough University, LE11 3TU, UK. Email: S.H.Yang@lboro.ac.uk.

\section{General STRUCTURE OF WIRELESS SENSOR NODE}

The architecture of the canonical node is showed in Fig. 1. From the view of the system functions, it is comprised of four subsystems [2]:

- A computing subsystem consisting of a microprocessor or microcontroller

- A communication subsystem consisting of a short range radio for wireless communication

- A sensing subsystem that links the node to the physical world and consists of a group of sensors and actuators

- A power supply subsystem, which houses the battery and the dc-dc converter, and powers the rest of the node.

In general, all of work, such as processing sensor data, implementing data fusion, managing system battery operation, setting parameters for sensors, and executing high-layer protocol, for instance, ZigBee specification, would be completed in the computing subsystem. Power consumption here is mainly caused by the microprocessor. Reducing operating voltage is one of the solutions for reducing power consumption. For example, when working under the conditions of CPU clock frequency $F_{\text {osc }}=4 \mathrm{MHz}$, working temperature $\mathrm{T}=25^{\circ} \mathrm{C}$, and PRI_RUN mode, which is normal, full power execution mode of the microcontroller, PIC18LF4620, a microprocessor produced by Microchip, consumes $4 \mathrm{~mW}$ at $\mathrm{Vcc}=2 \mathrm{~V}$, instead of $9 \mathrm{~mW}$ at $\mathrm{Vcc}=3 \mathrm{~V}$. Reducing CPU clock frequency within an allowing range is also one of the solutions to reduce power consumption. When $\mathrm{T}=25^{\circ} \mathrm{C}, \mathrm{Vcc}=5 \mathrm{~V}$, and PRI_RUN mode, the maximum power consumption of PIC18LF4620 is $30 \mathrm{~mW}$ at $\mathrm{F}_{\text {osc }}=4 \mathrm{MHz}$, but $200 \mathrm{~mW}$ at $40 \mathrm{MHz}$ [8]. Another method adapted by designers of microprocessors is to divide the work period of system device into the different modes (states) and to switch among those modes to make microprocessors run always in a powersaving state.

Communication subsystem mainly implements low-layer protocol, such as IEEE802.15.4, for transmitting and receiving data frames. It is well known that the RF module consumes a larger amount of energy in the communication and the distance of communication depends on the transmitting power. For instance, when the communication distance of the RF module xBee is lengthened from $100 \mathrm{~m}$ to $1.6 \mathrm{~km}$, the maximum power consumption rises from $0 \mathrm{dBm}$ to $20 \mathrm{dBm} \mathrm{[14][15].} \mathrm{The} \mathrm{routing} \mathrm{algorithms} \mathrm{with} \mathrm{energy}$ awareness, e.g., the Leach algorithm [19], indicate that a sensor node should use the corresponding amount of energy for transmitting when it plays a special role. In other words, the small transmitting power is used for the communication between a normal sensor node and the head of sensor nodes in a cluster; the large transmitting power has to be used for the 
long-distance communication between two head sensor nodes that belong to the different clusters. Therefore the RF module provides a mechanism to enable the transmitting power to be controlled by a program so that the energy of a sensor node can be effectively used. Sensor node locating is another focus in the WSNs research and there is a wide range of applications. The function is implemented in the RF module. CC2420, a product from Chipcon, locates the position of a node by the received signal strength indicator (RSSI) that can inspect and indicate the strength of receiving signal from this node [3].

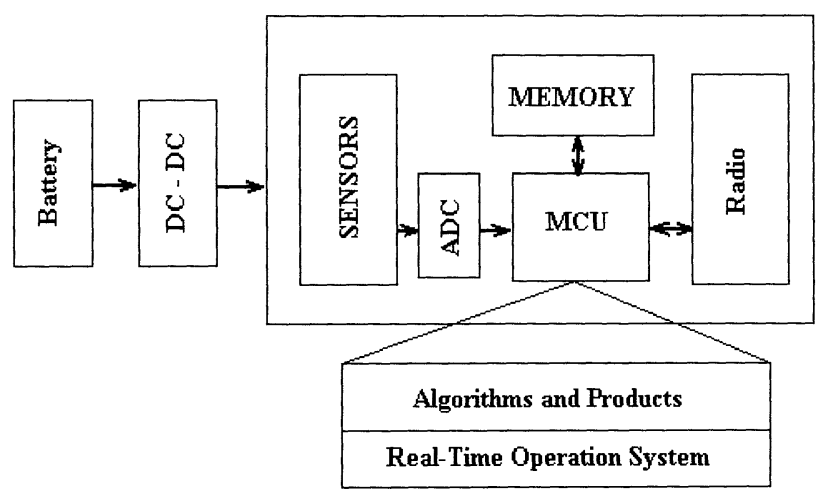

FIG. 1 SYSTEM ARCHITECTURE OF A WIRELESS SENSOR NODE

A sensing subsystem is generally divided into two types. One is a simple sensing device that includes sensor element that acquires information from the physical world around the node and converts it into analog signal, and then ADC converts the analog signal into digital value. The other is an intelligent sensing device that can provide functions such as automatic adjustment for a measure range, preprocessing sampling data, compensation for measure precision, high reliability, and so on, as well as all functions of a simple sensing device. It is necessary that a sensing subsystem provides an interface supporting the IEEE1451.2 protocol for the intelligent sensing device. Therefore it is convenient to match a standard device based on Plug-in and-Play.

Power supply subsystem consists of a battery, converter from direct current to direct current (dc-dc), and assistant control circuit. Sensor node driven by a battery might be often mobile for placing. The lifespan of sensor node depends on the energy stored in the battery. The dc-dc provides various voltages to support all devices in the system and makes them work in the different modes so that power consumption can be significantly reduced. The assistant control circuit maintains the routine works of the subsystem.

\section{TWO TYPICAL STRUCTURES OF WIRELESS SENSOR NODE}

Many famous chip manufacturers such as Chipcon, Microchip, Freescale, and so on, have presented their own solutions of wireless sensor networks, and provided corresponding products and development kits. Those products are divided into two categories according to their structures. One is designed by using the SoC solution; the other consists of components installed on a printing circuit board (PCB) such as RF module, microprocessor, and some electronic elements.

\section{A. Sensor node structure based on System-on-Chip (SoC)}

Sensor nodes based on a SoC structure integrate RF module, microprocessor, flash, RAM, analog-to-digital converter (ADC), and some special electronic circuits into a single chip. So it has very few external components, small volume, and high reliability. It is easy to develop for applications and the usage of this type of chip greatly shortens time for placing products to market. The performance of a sensor node is greatly improved because its system is designed as a whole.

CC2430/2431 manufactured by Chipcon is a pair of typical chips applied in wireless sensor nodes to support the IEEE802.15.4 protocol and ZigBee specification. CC2430 integrates the RF module CC2420, a 32MHz 8-bit 8051 core, an ADC, a $8 \mathrm{~KB}$ RAM, and a $128 \mathrm{~KB}$ flash. In CC2431, a location mechanism is integrated [3][4][5]. MC1321x is a series of products published by Freescale. A microcontroller based on the HCS08 Family of Microcontroller Units is included in MC1321x. The sizes of ROM and Flash can be selected according to the requirement of a design. MC13213 bundles the ZigBee protocol stack and MC13214 includes the Wireless ZigBee Stack software [21]. JN5121 developed by Jennic is a similar chip based on SoC with a $16 \mathrm{MHz} 32$-bit RISC core, and its structure is shown in Fig 2 [10].

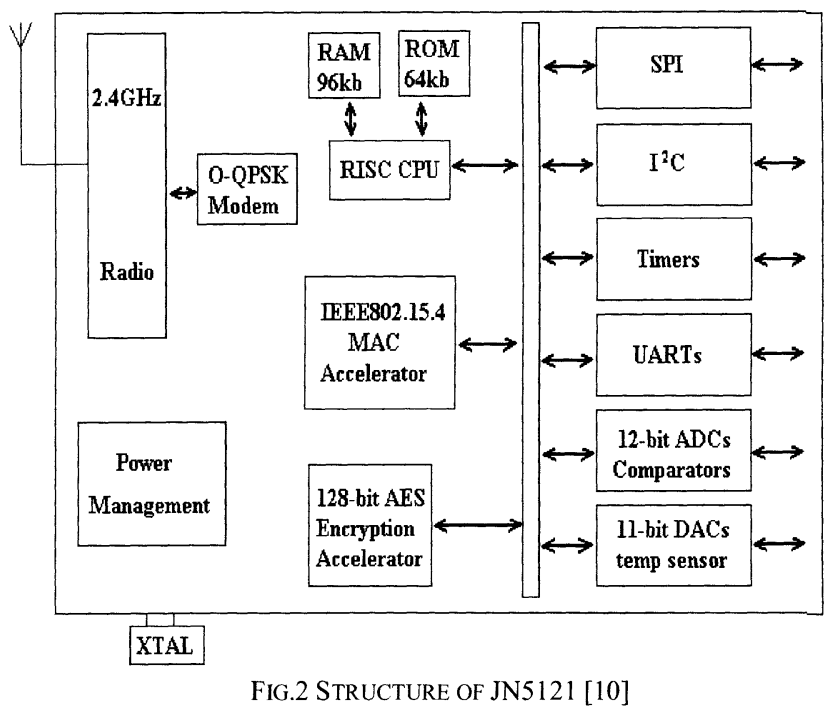

Before a sensor node is designed, it is important to select the chips according to their parameters. But it is not easy to balance energy consumption and system performance for the selection. It is known that the distance of communication between two sensor nodes dependents on the transmitting power of RF module. Usually users think, the longer the distance, the better the performance of system. But the longer the distance, the bigger the transmitting power required, which is the main part of power consumption in a sensor node, while power consumption depends on the supply 
voltage, supply current, and clock frequency of microprocessor and directly impacts the lifespan of wireless sensor node. Part of the parameters of CC2430, MC1321x, and JN5152 are listed in Table I. From Table I, it can be seen that three chips have nearly the same Operating Supply Voltage, but there are big differences among their power consumptions when they work on the receiving (RX) or transmitting (TX) mode and micro control unit (MCU) are active. Table I also provides a comparison of other features, such as memory, ADC, digital-to-analog converter (DAC) and MCU types.

TABLE I

PART OF THE PARAMETERS OF CC2430 AND JN5121

\begin{tabular}{|c|c|c|c|}
\hline Parameters & CC2430 & $\mathrm{MC} 1321 \mathrm{x}$ & JN5121 \\
\hline $\begin{array}{l}\text { Operating Supply } \\
\text { Voltage (Vdd) }\end{array}$ & $2.0 \sim 3.6 \mathrm{~V}$ & $2.0 \sim 3.4 \mathrm{~V}$ & $2.2 \sim 3.6 \mathrm{~V}$ \\
\hline $\begin{array}{l}\text { MCU active and } \\
\text { RX mode (Icc) }\end{array}$ & $27 \mathrm{~mA}$ & $37 \mathrm{~mA}$ & $<50 \mathrm{~mA}$ \\
\hline $\begin{array}{l}\text { MCU active and } \\
\text { TX mode (Icc) }\end{array}$ & $25 \mathrm{~mA}$ & $30 \mathrm{~mA}$ & $<40 \mathrm{~mA}$ \\
\hline $\begin{array}{l}\text { Maximum Transit } \\
\text { Power } \\
\end{array}$ & $0 \mathrm{dBm}$ & $2 \mathrm{dBm}$ & $1 \mathrm{dBm}$ \\
\hline $\begin{array}{c}\text { Power Down Mode } \\
\text { Current (Ipd) }\end{array}$ & $0.9 \mathrm{uA}$ & $1 \mathrm{uA}$ & $<5 \mathrm{uA}$ \\
\hline $\begin{array}{c}\text { Receiver } \\
\text { Sensitivity } \\
\end{array}$ & $-94 \mathrm{dBm}$ & $<-94 \mathrm{dBm}$ & $-93 \mathrm{dBm}$ \\
\hline Microprocessor & $\begin{array}{c}32 \mathrm{MHZ} 8 \text {-bit } \\
\text { Low power } 8051\end{array}$ & $\begin{array}{l}40 \mathrm{MHz} \\
\text { HCS08 } \\
\end{array}$ & $\begin{array}{c}16 \mathrm{MHZ} \\
\text { 32-bit, RISC }\end{array}$ \\
\hline Memory & $\begin{array}{l}32,64 \text {, or } 128 \mathrm{~KB} \\
\text { Flash, } 8 \text { KB RAM }\end{array}$ & $\begin{array}{c}\text { 1-4KB RAM } \\
16-60 \mathrm{~KB} \text { Flash }\end{array}$ & $\begin{array}{l}64 \text { KB ROM, } \\
96 \text { KB RAM }\end{array}$ \\
\hline $\mathrm{ADC}$ & $8-14$ bit ADC & $8-10$ bit $\mathrm{ADC}$ & 4-12 bit ADC \\
\hline DAC & & & $2-11$ bit DAC \\
\hline
\end{tabular}

$\mathrm{dBm}$ : $\mathrm{dB}$ referenced to one milliwatt. 8-14 bit $\mathrm{ADC}$ : an $\mathrm{ADC}$ with 8 channels and 14 bits each channel.

\section{B. Sensor node structure based on components}

The chip manufacturers provide various configuration schemes based on components for selection, in order to adapt the different applications and to achieve better performance, lower cost, and longer lifespan of sensor nodes. In this section, some solutions, supporting only the IEEE802.15.4 protocol and ZigBee specification, are listed, such as CC2420+ PIC181F4620 from Microchip [3][9], CC2420+C8051F121 from Silicon Laboratories [3][12][13], MC13192+MC9S08G (Fig 3) from Freescale [6][7]. These solutions are basically composed of two modules, RF module and microprocessor with special functions.

RF module supports the communication of sensor nodes and power management, for instance, CC2420 includes a single-chip, $2.4 \mathrm{GHz}$ and IEEE 802.15.4 compliant RF transceiver with a base-band modem, medium access control (MAC) support, hardware MAC encryption (AES-128), and battery monitoring. Its output power can be controlled by a program. Received signal strength can be indicated by digital value [3]. Power consumption, receiver sensitivity, and output power are still important objectives to be further improved for the design of the RF module. Some RF modules supporting the IEEE 802.15.4 protocol and their parameters affecting power consumption are listed in Table II. It can be seen that CC2420 has the smaller current when it works on RX or TX mode.

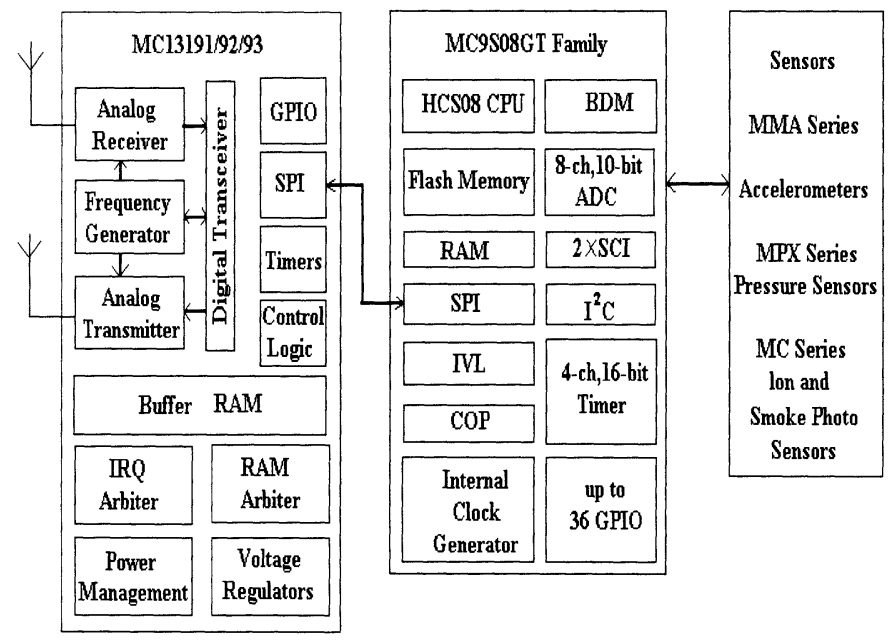

Fig.3 Solution based on MC1319x + MC9S08GT.

TABLE II (a)

PART OF THE PARAMETERS OF VARIOUS RF MODULES

\begin{tabular}{|c|c|c|c|c|}
\hline RF module & $\begin{array}{c}\text { Supply } \\
\text { Voltage }\end{array}$ & $\begin{array}{c}\text { RX mode } \\
\text { current }\end{array}$ & $\begin{array}{c}\text { TX mode } \\
\text { current }\end{array}$ & $\begin{array}{c}\text { Power down } \\
\text { mode current }\end{array}$ \\
\hline CC2420 & $2.1 \sim 3.6 \mathrm{~V}$ & $18.8 \mathrm{~mA}$ & $17.4 \mathrm{~mA}$ & $0.9 \mathrm{uA}$ \\
\hline MC13192 & $2.0 \sim 3.4 \mathrm{~V}$ & $42 \mathrm{~mA}$ & $35 \mathrm{~mA}$ & $1 \mathrm{uA}$ \\
\hline UZ2400 & $2.7 \sim 3.6 \mathrm{~V}$ & $18 \mathrm{~mA}$ & $22 \mathrm{~mA}$ & $2 \mathrm{uA}$ \\
\hline $\mathrm{xBee}$ & $2.8 \sim 3.4 \mathrm{~V}$ & $50 \mathrm{~mA}$ & $45 \mathrm{~mA}$ & $<10 \mathrm{uA}$ \\
\hline $\mathrm{xBee-PRO}$ & $2.8 \sim 3.4 \mathrm{~V}$ & $55 \mathrm{~mA}$ & $270 \mathrm{~mA}$ & $<10 \mathrm{uA}$ \\
\hline NanoPAN5360 & $2.4 \sim 3.6 \mathrm{~V}$ & $35 \mathrm{~mA}$ & $78 \mathrm{~mA}$ & $1.5 \mathrm{uA}$ \\
\hline NanoPAN5361 & $2.4 \sim 3.6 \mathrm{~V}$ & $35 \mathrm{~mA}$ & $78 \mathrm{~mA}$ & $1.5 \mathrm{uA}$ \\
\hline
\end{tabular}

TABLE II (b)

PART OF THE PARAMETERS OF VARIOUS RF MODULES

\begin{tabular}{|c|c|c|c|}
\hline RF module & $\begin{array}{c}\text { Maximum } \\
\text { Transmit Power }\end{array}$ & $\begin{array}{c}\text { Receiver } \\
\text { Sensitivity }\end{array}$ & $\begin{array}{c}\text { Modulation } \\
\text { Technique }\end{array}$ \\
\hline CC2420 & $0 \mathrm{dBm}$ & $-94 \mathrm{dBm}$ & DSSS \\
\hline MC13192 & $4 \mathrm{dBm}$ & $-92 \mathrm{dBm}$ & DSSS \\
\hline UZ2400 & $0 \mathrm{dBm}$ & $-95 \mathrm{dBm}$ & - \\
\hline xBee & $0 \mathrm{dBm}$ & $-92 \mathrm{dBm}$ & DSSS \\
\hline xBee-PRO & $20 \mathrm{dBm}$ & $-100 \mathrm{dBm}$ & DSSS \\
\hline NanoPAN5360 & $6 \mathrm{dBm}$ & $-90 \mathrm{dBm}$ & CSS \\
\hline NanoPAN5361 & $8 \mathrm{dBm}$ & $-92 \mathrm{dBm}$ & CSS \\
\hline
\end{tabular}

DSSS: direct sequence spread spectrum.

CSS: chirp spread spectrum.

The performance of a microprocessor built in sensor nodes can be evaluated by the power consumption, calculation capability, and transfer rate between system and RF module. In general, the higher the supply voltage and the faster the clock frequency of CPU, the higher the transfer rate and the stronger the calculation capability, but the higher the power consumption required. High power consumption will reduce the lifespan of sensor nodes. In addition, the size of the data that can be processed by the microprocessor indicates the calculation capability. The key problem is how to acquire the high performance of system by selecting parameters such as supply voltage and clock frequency. A large memory of both ROM/Flash and RAM must be integrated into the 
microprocessor so to support the running of the protocol stack. In order to save the space of sensor node and reduce the complexity of system, an ADC is usually integrated into the chip. Some parameters of ADC, such as maximum sampling frequency, precision, and number of channels, must be considered when a microprocessor is selected for building a sensor node. Typical microprocessors used in sensor nodes and some of their parameters are listed in Table III.

TABLE III

TYPICAL MICROPROCESSORS AND SOME OF THEIR PARAMETERS

\begin{tabular}{|c|c|c|c|c|}
\hline Microprocessor & C8051F121 & PICF4620 & MC9s08GT & ATMEGA128L \\
\hline $\begin{array}{l}\text { Supply Current } \\
\text { (Run mode) }\end{array}$ & $\begin{array}{c}\mathrm{Vdd}=2.7 \mathrm{~V}, \\
\mathrm{Icc}=25 \mathrm{~mA}, \\
@ 50 \mathrm{MHZ}\end{array}$ & $\begin{array}{l}\mathrm{Vdd}=4.2 \mathrm{~V}, \\
\mathrm{Icc}=16 \mathrm{~mA}, \\
@ 40 \mathrm{MHZ}\end{array}$ & \begin{tabular}{|c|}
$\mathrm{Vdd}=3 \mathrm{~V}$, \\
$\mathrm{Icc}=6.5 \mathrm{~mA}$, \\
$@ 16 \mathrm{MHZ}$
\end{tabular} & $\begin{array}{c}\mathrm{Vdd}=3 \mathrm{~V}, \\
\mathrm{Icc}=5.5 \mathrm{~mA}, \\
@ 4 \mathrm{MHZ}\end{array}$ \\
\hline $\begin{array}{l}\text { Supply Current } \\
\text { (Power down mode) }\end{array}$ & $\mathrm{Ipd}=0.4 \mathrm{uA}$ & $\begin{array}{r}\mathrm{Vdd}=3 \mathrm{~V}, \\
\mathrm{Ipd}=0.1 \mathrm{uA}\end{array}$ & $\begin{array}{c}\mathrm{Vdd}=3 \mathrm{~V} \\
\mathrm{Ipd}=2.5 \mathrm{uA}\end{array}$ & $\begin{array}{l}\mathrm{Vdd}=3 \mathrm{~V} \\
\mathrm{Ipd}<5 \mathrm{uA}\end{array}$ \\
\hline Supply Voltage & \begin{tabular}{|c|}
$2.7 \sim 3.6 \mathrm{~V}($ \\
$50 \mathrm{MIPS})$ \\
$3.0 \sim 3.6 \mathrm{~V}$ \\
$(100 \mathrm{MIPS})$
\end{tabular} & $2.0 \sim 5.5 \mathrm{~V}$ & $1.8 \sim 3.6 \mathrm{~V}$ & $2.7 \sim 5.5 \mathrm{~V}$ \\
\hline Clock & $\begin{array}{c}\text { Up to } \\
100 \mathrm{MHZ}\end{array}$ & $\begin{array}{l}\text { Up to } \\
\text { 40MHZ }\end{array}$ & $\begin{array}{l}\text { Up to } \\
40 \mathrm{MHZ}\end{array}$ & Up to $8 \mathrm{MHZ}$ \\
\hline ROM & $\begin{array}{l}128 \mathrm{~KB} \\
\text { Flash }\end{array}$ & $\begin{array}{c}64 \mathrm{~KB} \text { Flash } \\
1024 \text { Bytes } \\
\text { EEPROM }\end{array}$ & $\begin{array}{l}\text { Up to } 60 \\
\text { KB Flash }\end{array}$ & $\begin{array}{c}4 \mathrm{~KB} \\
\text { EEPROM } \\
128 \mathrm{~KB} \\
\text { Flash }\end{array}$ \\
\hline RAM & $8 \mathrm{~KB}$ & $3986 \mathrm{~KB}$ & Up to $4 \mathrm{~KB}$ & 4KB SRAM \\
\hline $\mathrm{MCU}$ & $\begin{array}{c}\text { High } \\
\text { Speed } \\
8051 \mathrm{uC}\end{array}$ & 8-bit PIC core & $\begin{array}{c}8 \text {-bit } \\
\text { HCS } 08 \text { core }\end{array}$ & $\begin{array}{l}\text { Advanced } \\
\text { RISC } \\
\text { Architecture }\end{array}$ \\
\hline Port & $\begin{array}{c}48 \mathrm{I} / \mathrm{O} \\
\text { pins }\end{array}$ & $36 \mathrm{I} / \mathrm{O}$ pins & $\begin{array}{c}56 \mathrm{I} / \mathrm{O} \\
\text { pins }\end{array}$ & $53 \mathrm{I} / \mathrm{O}$ pins \\
\hline $\mathrm{ADC}$ & $\begin{array}{c}12 \text {-bit } \\
100 \mathrm{ksps} \\
8 \text {-bit } \\
500 \mathrm{ksps}\end{array}$ & $\begin{array}{c}13 \text { channels } \\
10 \text { bits each } \\
\text { channel }\end{array}$ & $\begin{array}{c}8 \text { channels } \\
10 \text { bits } \\
\text { each } \\
\text { channel }\end{array}$ & $\begin{array}{c}8 \text { channels } \\
10 \text { bits each } \\
\text { channel }\end{array}$ \\
\hline
\end{tabular}

\section{Special Requirements of Wireless Sensor Nodes FOR BUILDING FIRE SAFETY}

When a wireless sensor network is applied to building fire safety, there are many requirements to be considered in the design of sensor nodes.

For sensing subsystem, it should support the various kinds of sensor elements for sensing physical characteristics such as temperature, pressure, chemical gas, humidity, infrared ray, voice, vibration, etc. Therefore the connection mode between sensors with sensor nodes must be designed at first. One way is a single sensor node with various sensors. The power consumption of the node may be greatly increased. A large requirement of memory will be required because the program in the node needs to process a lot of data from the different sensors. The other is that one sensor node is only connected to one special sensor and an inspecting point consists of a group of sensor nodes with the various sensors. How to effectively place these sensor nodes in a building environment and how to design a unified format of data frame that suits to frame the different types of data are worthy of being considered. In order to achieve the compensation of high precision and high reliability, and to adjust the measure range automatically, it is natural to use intelligent sensor devices with Plug-in-Play. So the sensing subsystem should provide an interface to support the IEEE1451.2 protocol.

After the communication chain in a multi-hop wireless sensor network is broken during the emergency, a sensor node in the network may be required to change its role from executing a sensor function to undertaking a communication mission. So the communication subsystem should provide the mechanism that increases the transmitting power so that the communication distance can be extended, for example, from $100 \mathrm{~m}$ to $1.6 \mathrm{~km}$.

It is easy to recycle sensor nodes used in building fire safety after their lifespan expire because they are installed inside a building. The rechargeable battery might be a good option. The power supply subsystem should provide a mechanism just like SplashPads [20] to support the wireless rechargeable implementation.

\section{A POSSIBLE HARDWARE ARCHITECTURE OF SENSOR NODE WITH ENERGY AWARENESS}

The function of a sensor node mainly consists of two parts. One is to capture information from the physical environment around this node, process data acquired according to the requirements, convert these data into a data frame, and transmit the data frame. The other is to relay data frames from other sensor nodes in the multi-hop wireless sensor network. The microprocessor in the sensor node spends the majority of time to run those routine transactions during the lifespan of the sensor node. Therefore a mass of energy is consumed for the routine work. In order to save energy, the microprocessor can be running in a power-saving sleep mode or a power down mode when there is no event occurring. Frequently waking CPU to respond interrupting events, for example, to relay data frames from other nodes in an outburst of transmitting, requires the system quickly switching from a sleep mode to a work mode. Some data frames may be lost if the system responds slowly. The cost of a sensor node rises, as it is necessary to use high performance components to build a system with fast response.

It may be possible to prolong the period when a sensor node processes routine transaction in a low power consumption state, while the microprocessor in a sensor node sleeps synchronously in power down mode as long as possible. It is only waked up when either the abnormal events occur or the current system mode must be changed.

It may be a better choice to use a CoolRunner CPLD, the product of Xilinx, for assisting a microprocessor to process routine transaction. CPLD is a complex programmable logic device with low power consumption, high clock frequency, and advanced design security. It provides the multi-voltage $\mathrm{I} / \mathrm{O}$ operation to support the various elements in the system. Many components based on both combinational logic circuits and timing logic circuits can be implemented by 
programming in CPLD. It is very important that CPLD can complete the majority functions of a MCU and run in a state with very low power consumption. For example, when working under the conditions of $\mathrm{F}_{\mathrm{osc}}=50 \mathrm{MHz}, \mathrm{T}=25^{\circ} \mathrm{C}$, and LVCMOS 1.8V, XC2C64 CoolRunner-II, a product of Xilinx company, only consumes $6.66 \mathrm{~mW}$, while the maximum power consumption of PIC18LF4620 is $200 \mathrm{~mW}$ at $40 \mathrm{MHz}$, $\mathrm{T}=25^{\circ} \mathrm{C}, \mathrm{Vcc}=5 \mathrm{~V}$, and PRI_RUN mode. So, if CPLD is used to process routine transaction instead of a $\mathrm{MCU}$, the power consumption will be greatly reduced. XC2C64 supports the frequencies in the range from 0 to $240 \mathrm{MHz}$ and provides the mixed $\mathrm{I} / \mathrm{O}$ voltages compatible with $1.5 \mathrm{~V}, 1.8 \mathrm{~V}, 2.5 \mathrm{~V}, 3.3 \mathrm{~V}$ logic levels [17]. The block diagram of the scheme centering the routine transaction of wireless sensor node is shown in Fig. 4 and part of the parameters of XC2C64 CoolRunner-II, are listed in Table IV.

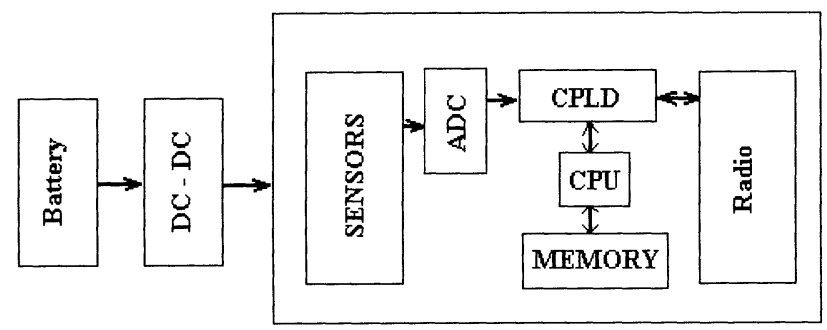

Fig.4 A scheme centering the routine transaction of wireless sensor node

TABLE IV

ICC vs. FREQUENCY (LVCMOS $1.8 \mathrm{~V} \mathrm{~T}=25^{\circ} \mathrm{C}$ )

\begin{tabular}{|c|c|c|c|c|c|c|c|c|c|}
\hline ICC vs. FREQUENCY (LVCMOS $\left.1.8 \mathrm{~V} \mathrm{~T}=25^{\circ} \mathrm{C}\right)$ \\
\hline Freq. (MHZ) & 0 & 25 & 50 & 75 & 100 & $\begin{array}{c}15 \\
0\end{array}$ & $\begin{array}{c}17 \\
5\end{array}$ & $\begin{array}{c}20 \\
0\end{array}$ & 225 \\
\hline Icc(mA) & 0.015 & 1.8 & 3.7 & 5.5 & 7.48 & 11.0 & 12.7 & 14.6 & 15.3 \\
\hline
\end{tabular}

In the implementation of this new architecture of a sensor node, the following problems should be addressed:

- How to define the routine transaction and separate it from the real-time operation system, and then implement it in CPLD.

- How to design an interface with RF module in CPLD, for example, SPI.

- It is needed to take cost, power consumption, and volume into consideration when replacing $\mathrm{ADC}$ in a microprocessor with an independent element.

- How to implement an interface to support the IEEE 1451.2 protocol in CPLD.

- How to implement the function of a power supply subsystem in CPLD.

- How to evaluate the synthetic performance of the new architecture.

A number of research and experiments need to be done to explore whether this architecture can greatly improve the performance of wireless sensor node or not.

\section{CONCLUSION AND FUTURE WORK}

It may be an effective method to use a low power chip for implementing the routine transaction of microprocessor, consequently, to keep the microprocessor in a power down mode in order to significantly reduce power consumption of wireless sensor nodes. The key problem is to look for a strategy to make a dynamic tradeoff among factors that impact system performance. The future work is to implement the solution on the platform consisting of CC2420, CoolRunner CPLD, and PIC18F4620 and to compare it with the system without using CPLD.

\section{REFERENCES}

[1] Jamal N. Al-Karaki, Ahmed E. Kamal, "Routing Techniques in wireless sensor networks: A survey," Wireless Communications, IEEE, Volume 11, Issue 6, 2004, pp. 6-28.W.-K. Chen, Linear Networks and Systems (Book style). Belmont, CA: Wadsworth, 1993, pp. 123-135.

[2] V.Raghunathan, C. Schurgers, S. Park, and M.B. Srivastava, "Energy aware wireless microsensor networks," Signal Processing Magazine, IEEE, Volume 19, Issue 2, Mar. 2002, pp. 40-50.

[3] SmartRF CC2420 Data Sheet, Chipcon.

[4] SmartRF CC2430 Data Sheet, Chipcon.

[5] SmartRF CC2431 Data Sheet, Chipcon.

[6] MC13192/MC13193 Data Sheet, Freescale Semiconductor.

[7] MC9S08GB/GT Data Sheet, Freescale Semiconductor.

[8] PIC18F2525/2620/4525/4620 Data Sheet, Microchip.

[9] PICDEM ${ }^{\mathrm{TM}} \mathrm{Z}$ DEMONSTRATION KIT USER'S GUIDE, Microchip.

[10] Product Brief - JN5121, Jennic.

[11] ATmega 128/Atmega128L Data Sheet, ATMEL.

[12] C8051F120/1/2/3/4/5/6/7 Data Sheet, Silicon Laboratory.

[13] AN222 Data Sheet, Silicon Laboratory.

[14] Datasheet_XBee_OEM-RF-Module, XBee.

[15] XBee $\mathrm{XM}^{\mathrm{TM}} / \mathrm{XBee} \mathrm{PRO}^{\mathrm{TM}}$ OEM RF Modules Product Manual, XBee.

[16] nanoNET TRX Transceiver (NA1TR8) Datasheet, nanotron.

[17] XC2C64 CoolRunner-II CPLD Product Specification, Xilinx.

[18] Decrease Processor Power Consumption using a CoolRunner CPLD, xapp:347, Xilinx.

[19] Wendi B. Heinzelman, Anantha P. Chandrakasan, Hari Balakrishnan, "An Application-Specific Protocol Architecture for Wireless Microsensor Networks", IEEE TRANSACTIONS ON WIRELESS COMMUNICATIONS, VOL. 1, Issue 4, Oct. 2002.

[20] Splashpower Announces Universal Wireless Recharging, ww.splashpower.com.

[21] MC13211/212/213/214 Technical Data . Freescale Semiconductor.

[22] UZ2400 Data Sheet (RF+Baseband+MAC) Uniband Electronic Corp. 